\title{
Trial of liquidation cementation of boreholes at Carpathians oil and gas deposits
}

\author{
Kovalchuk M. ${ }^{1}$, Tershak B. ${ }^{1}$, Cheliadyn L. ${ }^{1}$, Sobol Kh. ${ }^{2}$, Terlyha V. \\ ${ }^{1}$ Ivano-Frankivsk National Technical University of Oil and Gas \\ ${ }^{2}$ Lviv Polytechnic National University
}

\begin{abstract}
Complex geological structure as well as long-term intensive operation of oil and gas deposits in Borislav-Pokutska zone of Carpathians leads to changes in thermodynamical parameters of pools, rock deformation and, as a result, to crippling of the boreholes and creasing and damaging of boring casing. The abovementioned actions not only complicate extraction of oil and gas but increase the technological charge on the environment. In this study 3 types of materials were investigated: PCT-I-100 - traditional tamping cement, CREA and CREA-LF tamping mixes produced by dry mixing technology that were designed by authors. Dry mixes are characterized by higher level of $\mathrm{SiO}_{2}$ because of addition of milled sand and provide better cementation quality. Developed materials are characterized by lower dehydration and water reduction, thanks to clearly chosen composition and modern chemical admixtures usage. The method of borehole eliminative cementation is also presented by authors.
\end{abstract}

Key words: borehole, dry plugging mixes, cementation, dehydration, chemical admixtures, boring casing

\section{Problem statement}

Long-term intensive exploitation of petroleum and gas deposits of Carpathian, where during XIX - XXI centuries thousands of oil and gas boreholes have been built, the change of deposit thermodynamic characteristics intensified by deformation of mountain beds, not only complicates the production of oil and gas but increases the technogenic influence on an environment [1], first of all through breaking of timbering integrity, damaging of casing and out-of-control fluidizing. The problem of reliable liquidation cementation of old boreholes is a burning issue for the deposits of hydrocarbons of Boryslavsky, Dolynsky and Nadvirniansky oil industry districts that are situated near resorts Truskavets, Skhidnytsia, Morshin, Bukovel and create the real threat to the environment in a cross-border region.

The great majority of old boreholes are characterized by multistring well program construction. One of them (Stateland- 19), drilled in 1932 at a depth of 1278 meters, has 11columnar construction (22" - 0-13,7 m; 20" - 0-47,4 m; 18" - 0-59,7 m; 16" - 0-248,6 m; 14" - 0-426,0 m; 12" - 0-545,0 m; 10" - 503-734,6 m; 9" - 679-1070,8 m; 7" - 0-1243,0 m; 6" - 1065-1530 m; 5" - 1420-1536 m.). The other - (Bank-1), drilled in 1930 at a depth of $830 \mathrm{~m}$ has 12- columnar construction of borehole (23" - 0-18,0 m; 22,5" - 0-30,0 m; 21" 27-49,6 m; 17" - 42-70,7 m; 16" - 104-136,6 m;15" - 131-157,3 m; 14" - 155,9-180 m; 13" - 172,6-205 m; 12" - 195-224,2 m; 10" - 219-266,5 m; 9" - 0-299 m; 7" - 299-452,0 m). As a rule, casing has not been cementating, but rather has been tamping by clay, therefore some cases of depressurization of a mouth followed by the out-of-control periodic discharges of bed fluids on a daily surface with further spontaneous combustion (Fig.1). 


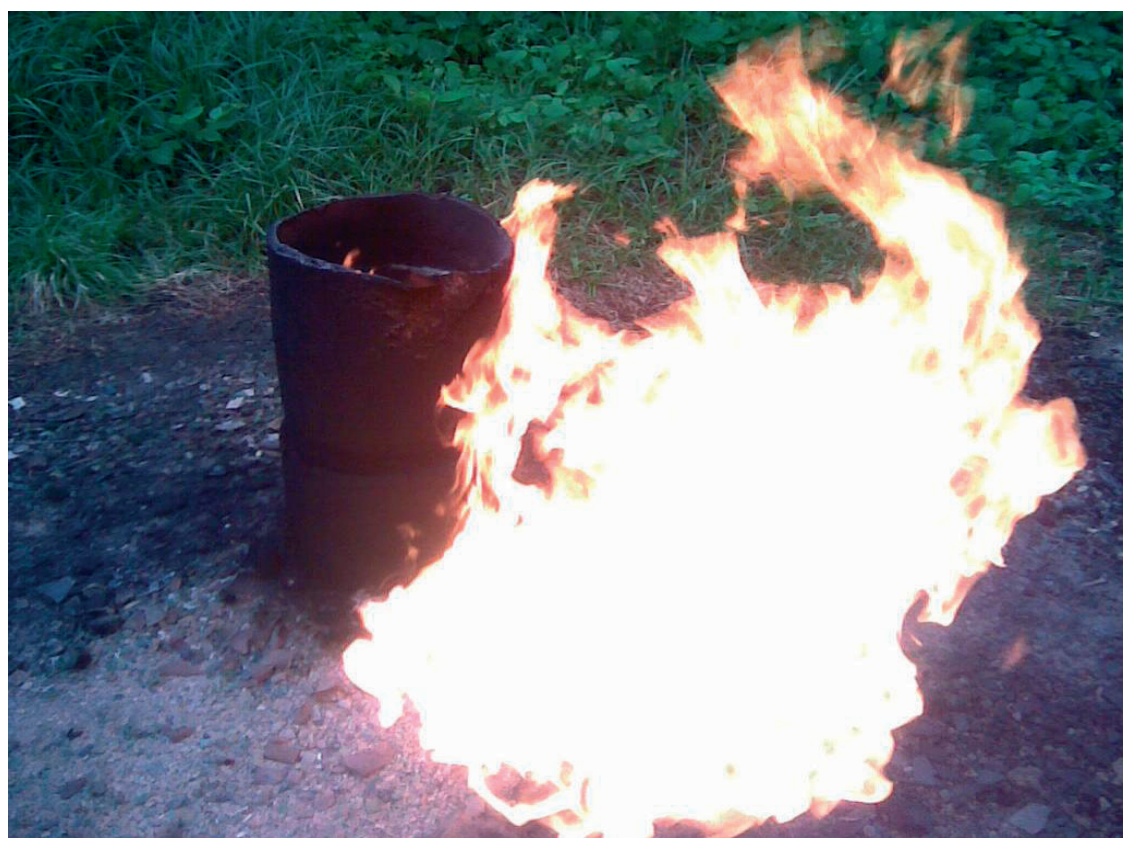

Fig. 1. Actual state of the mouth of the borehole 131 Old Mine

To ensure the necessary level of reliability of the borehole casing, as an engineering structure, it is required to develop plugging material which is able to form durable corrosion-resistant cement stone, methods, by which the technological properties can be regulated, and process control of the mix structure formation; and, besides, unconventional approaches to the technology of barrier installation must be designed.

\section{Analysis of the recent investigations and publications}

The standard technology of liquidation works stipulates isolation of production horizons and the sources of fluidic-flow appearing, that can causes interstratal crossflows or migration on a daily surface, and also equipment of a heel of a borehole according to a previously considered chart. Such order of the work realization, as a rule, provides warning of crossflows of fluid and gryphon creating. At the same time, the problem of repeated borehole isolation can be arisen, as the quantity of them, as for example in Boryslav NPR, amounts to 151. Formation pressure in such boreholes is essentially lower than hydrostatic, boring casing is incoronated and, according to geophysical data, has through defects (fig. 2). 


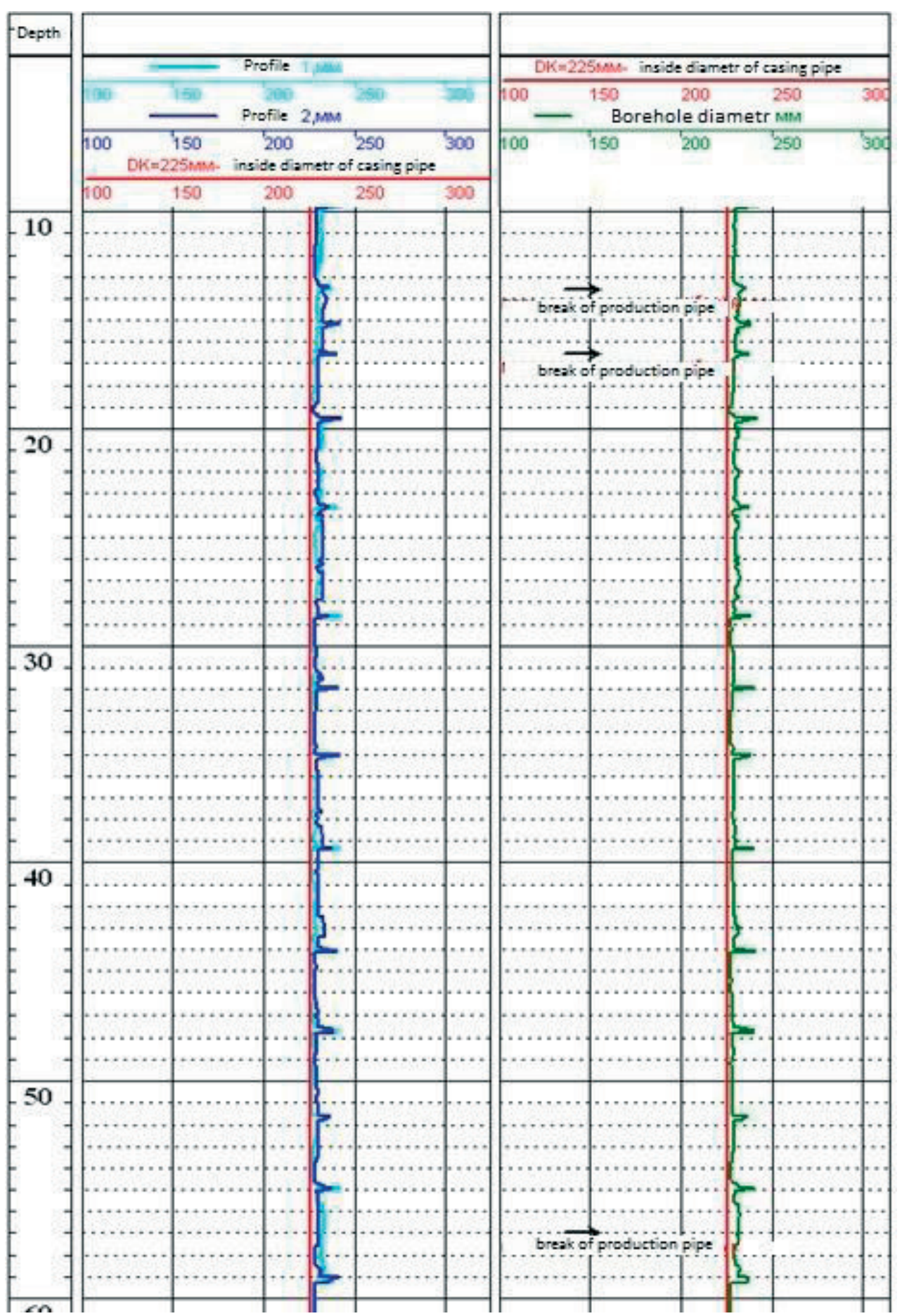

Fig. 2. State of the flow tubing borehole № 699 Boryslav according to GDC data 


\section{Purpose of the work}

Development of current trend plugging materials and improvement of technology of isolation works with the aim to provide repeated liquidation plugging of the old boreholes at oil and gas deposits of Carpathians region.

\section{Methods of investigation and materials}

In the research, the plugging cement PCT-I-100 produced by JSC „Volyncement” of the following composition: $\mathrm{CaO}-66,4 \%, \mathrm{SiO}_{2}-21,4 \%, \mathrm{Fe}_{2} \mathrm{O}_{3}-3,5 \%, \mathrm{Al}_{2} \mathrm{O}_{3}-5,25 \%$, others $-3,45 \%$ with specific surface $295 \mathrm{~m}^{2} / \mathrm{kg}$, produced in accordance with DSTU B.V.2.7-88-99 (ГОСТ 1581-96); complex expanding plugging mortar CREA i CREA-LF produced by Ltd. «Gelios» (Lviv) of the following composition - $\mathrm{CaO}-57,71 \%, \mathrm{SiO}_{2}-$ $26,4 \%, \mathrm{Fe}_{2} \mathrm{O}_{3}-2,35 \%, \mathrm{Al}_{2} \mathrm{O}_{3}-5,89 \%$, others $-7,65 \%$ with specific surface $335 \mathrm{~m}^{2} / \mathrm{kg}$; Carpathians zeolitic tuff - a group of alumosilicates of the following composition: clinoptilolite $\left(\mathrm{Na}_{2} \mathrm{O}_{*} * \mathrm{Al}_{2} \mathrm{O}_{3} * 10 \mathrm{SiO}_{2} * 8 \mathrm{H}_{2} \mathrm{O}\right) 60-82$ mas.\%, quartz 10-20 mas.\%; mica and feldspar 5-20 mas.\%; thermographinite - thermo expanding inflated graphite produced by Ltd. «TMSpecmash» (Kyiv). Kneading liquid - water. The properties of plugging mortars and cement stone were determined in accordance with DSTU B V.2.7-88-99 «Pluging cements. Technical specifications», DSTU B V.2.7-86-99 "Pluging cements. Methods of testing", and SOU 11.2-0013590: 2012 "Boreholes for oil and gas. The order of receipt and storage of cement. Batching and preparing of plugging mortar".

The structure of cement stone was studied by the method of electronic scanning microscopy, X-ray diffraction method, method of mercury pore meter. The studies of the dynamics of strength characteristics of cement stone in thermo baric conditions were implemented by non-damaging method according to API using ultrasonic cement analyzer (UCA) from the company OFI Testing Equipment Inc. (№120-50).

\section{Results of research}

Microstructure of the Portland cement stone PCT-I-100 at W/C $=0,48-0,5$ has been characterized by diversified morphology. Alongside with fine-grain lamellar hydrates on the surface of cement grains, the system of pores, which are connected to each other and create the capillary-porous structure, has been observed. Quite high value of W/C ratio increases the role of the cement stone crystalline component which disposes in the pore space. The hydrated products are presented by ettringite, hexagonal $A_{\mathrm{m}}$-phases, calcium hydroxide and fibrous hydrosilicates. Water-cement ratio exerts large influence on early hydration process of Portland cement, especially determining kinetics of calcium hydrosulphoaluminate formation. Increasing of the ettringite content at increasing values of $\mathrm{W} / \mathrm{C}$ is caused by enhancing of speed of $\mathrm{Ca}^{2+}$ and $\mathrm{SO}_{4}{ }^{2-}$ ions movement in the liquid. High concentration of sulphate ions was holding during certain time depending on the alkali content in the cement, that is the higher alkali content in the cement and the earlier dissolution begins, the faster decrease supersaturation of the solution by calcium ions. Liquid phase composition in the hardening system "cement - water" has been changing steadily. That results in recrystallization of hydrated compounds during all the period of cement stone operating. To improve operational characteristics of cement stone it is expedient to decrease in its microstructure the quantities and sizes of largely crystallized hydrated formations (calcium hydroxide, hydroalumoferite, hydrosulphoalumoferite), alongside with increase of metamict content of hydrated compounds. 
Composites CREA and CREA-LF, despite the larger specific surface, that promote binding of excess water, and lower water-cement ratio, are characterized by better stability, and structurally rheological and filtration properties. Therefore, dehydration of the CREA mixture has been decreased by $64,7 \%$, and for the mixture with CREA-LF - it came to zero, that is especially important for the casing of boreholes with complicated space architecture. Bending strength of the stone increased by $44,9 \%$ for CREA and by $55,1 \%$ for CREA-LF. At the same time the structure formation incubation period was shorter. This ensure formation of the stone with denser structure, closing of larger quantity of hydrate surface active centers in contact interactions in comparison with the reference specimen based on PCT-I-100.

Addition of clinker minerals of calcium sulphoferites, as crents, to the base composite cement promote and provide the possibility of directed synthesis of materials with improved properties (linear expansion of cement stone, minimum heat release, increase of structure density, durability and corrosion resistance, and also ability to self-reinforcing and self-healing of structure defects, that arise up as a result of the dynamic loading during exploitation) [3].

Table 1. Results of comparative tests PCT I-100, CREA and CREA-LF

\begin{tabular}{|c|c|c|c|c|c|}
\hline \multirow{3}{*}{ No. } & \multirow{3}{*}{ Item } & \multicolumn{4}{|c|}{ Index value } \\
\hline & & \multirow{2}{*}{$\begin{array}{l}\text { Acc. to } \\
\text { DSTU }\end{array}$} & \multirow{2}{*}{ PCT-I-100 - } & \multicolumn{2}{|c|}{ Composite mortars } \\
\hline & & & & CREA & CREA-LF \\
\hline 1 & $\begin{array}{l}\text { Grinding fineness - sieve residue with grid №.008 } \\
\text { according to GOST 6613, not more than, \%, }\end{array}$ & 15 & 11,8 & 3,4 & 4,8 \\
\hline 2 & Specific surface, $\mathrm{m} 2 / \mathrm{kg}$, no less than & - & 285 & 315 & 320 \\
\hline 3 & Density of cement suspension , $\mathrm{g} / \mathrm{cm} 3$ & - & 1,82 & 1,86 & 1,85 \\
\hline 4 & Water-cement ratio & 0,5 & 0,48 & 0,45 & 0,45 \\
\hline 5 & Dehydration,ml, not more & 8,7 & 7,0 & 1,5 & 0 \\
\hline 6 & Spreadability of cement past, $\mathrm{mm}$, not less than & 200 & 195 & 230 & 225 \\
\hline 7 & Thickening time to30 Berden units, min. not less than & 90 & 90 & $>100$ & $>100$ \\
\hline \multirow{2}{*}{8} & \multirow{2}{*}{ Setting time, hour-min. } & - & $1-30$ & $1-45$ & $2-00$ \\
\hline & & - & $2-10$ & $2-25$ & $2-15$ \\
\hline \multirow{2}{*}{9} & \multirow{2}{*}{$\begin{array}{l}\text { Strength of cement stone, } \mathrm{MN} / \mathrm{m} 2 \\
\text { not less than, after } 1 \text { day }\end{array}$} & 3,5 & 4,9 & 7,1 & 7,6 \\
\hline & & - & 18,1 & 17,6 & 18,4 \\
\hline 10 & Linear expansion of cement stone, $\%$ & - & - & 1,5 & 1,2 \\
\hline 11 & & - & 640 & 170 & 15,5 \\
\hline \multicolumn{6}{|c|}{$\begin{array}{l}\text { Rheological characteristics at } 27 \mathrm{o} \text { C according to } \\
\text { FAN35 at }\end{array}$} \\
\hline & $600 \mathrm{rpm}$ & \multirow{6}{*}{-} & 120 & 150 & 170 \\
\hline & $300 \mathrm{rpm}$ & & 80 & 95 & 105 \\
\hline & $200 \mathrm{rpm}$ & & 55 & 60 & 90 \\
\hline & $100 \mathrm{rpm}$ & & 40 & 45 & 70 \\
\hline & $60 \mathrm{rpm}$ & & 35 & 35 & 55 \\
\hline & $30 \mathrm{rpm}$ & & 20 & 25 & 45 \\
\hline
\end{tabular}

Character of formation of crystallization structure of composition materials modified by crents differs slightly from this of Portland cement and begins, when the size of hard phase nuclei, that arise up on the coagulative stage of solidification, exceeds the critical one, and directly depends on chemical nature of phases of the solidificating system, 
saturation degree of solutions hydrated new formations and surface tension coefficient on the interphase boundary. Speed of crystallizational framework formation is regulated by the diffusion coefficient of colloid particles from oversaturated solutions of hydrated new formations to the hard phase nuclei. As crystals of hydrated composition minerals are different by form and size of elementary cells, then in the process of their development the linear defects of structure are intensively created - distributions of disparity and point defects-vacancies. Crystals develop athwart to the surface of matrix in direction to the nearest aquated particles of the binder, and serve as the centers of nucleation and crystallizations, on which further hydrated products are besieging (Fig. 3). Composition materials are characterized by more even distribution of hydrates in gel mass of hydrosilicates, better ordering of coalescence contact zones and increase of amount of coalescenced fibres in the hydrosilicates blocks. The above mentioned provides formation of denser structure of the stone and closing of greater number of active hydrate surface centers in the contact interaction in comparison with a reference specimen on the base of cement of PCT-I-100; that ensure the improvement of strength characteristics and deformation properties of the cement stone formed from the composition materials. Therefore, optimal combination of polymineral components of different genesis provides the directed synthesis of cement stone with the improved operating properties at thermobaric conditions.

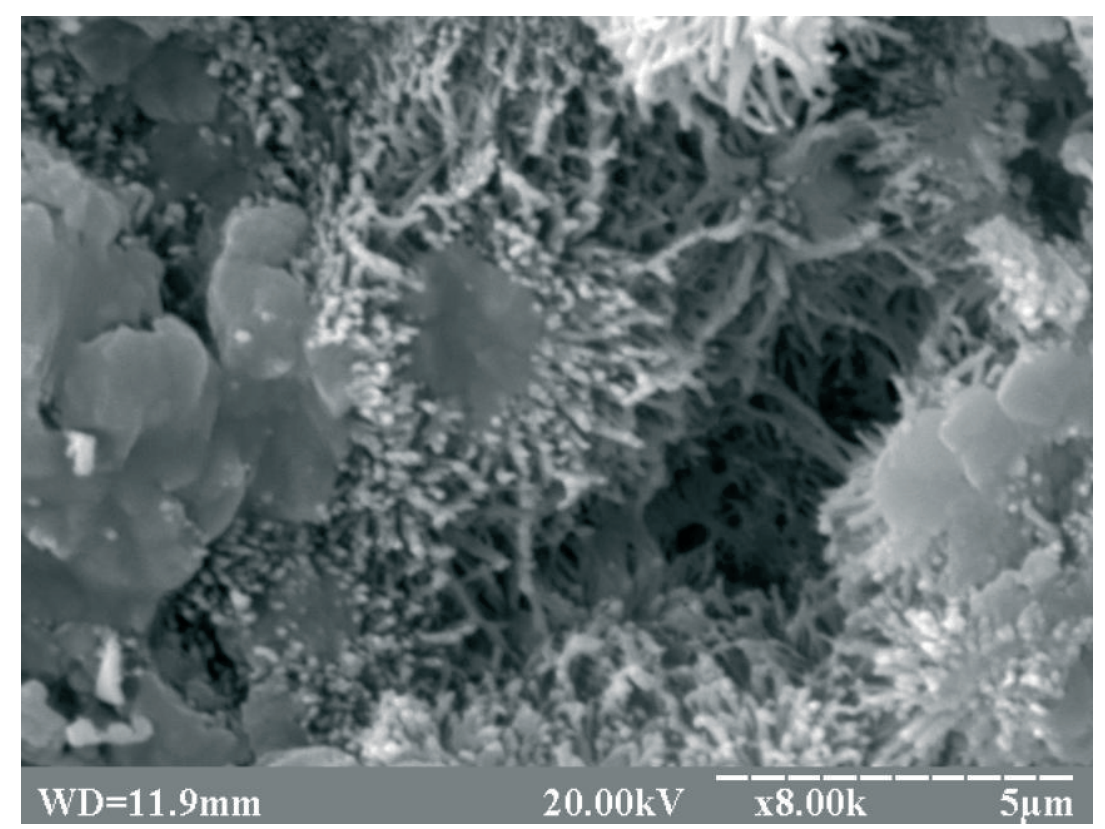

Fig. 3. Structure of cement stone CREA

The distinguishing characteristic of microstructure provided the matrices, on the basis of the modified composition cement, with increasing viscosity of destruction of cracks of the normal tearing away, higher indicators of durability and resiliency at a bending through the mechanism of breaking of development and confluence of microcracks by structural heterogenities - microreinforcing fibres, gel pores, microcapillars, by the surfaces of phases division, by grains of mineral additives and clinker, that were not used in the process of 
hydratation, as well as by crystals It means that phases, that appear during hydratation of composition cement, are identical with those that appear during hydration of PCT-I-100. The difference consists in a quantitative relationship between the low-basic and high-basic calcium hydrosilicates.

The improvement of cement stone characteristics of CREA and CREA-LF composition mixtures is promoted by application of polyfunctional modifiers. It is known that, physic-mineralogical composition of cement, nature of additions-modifiers, solidification conditions stipulate such qualificatory descriptions of microstructure, as composition and basicity of new formations, crystal morphology, type of bonds, character of porosity, correlation of gel-like and crystalline phases, and also intensity of structure formation and destruction processes of the stone. On the basis of the research results optimal correlations of compositions binders capable to self-reinforcing, phase composition of hardened products and kinetics of expansion were determined and technological properties were studied. It is stated that increase of efficiency of crents can be achieved by introducing complex additives of polyfunctional action, that, complementing each other, allow to get additive, and occasionally synergistic effects [4].

A plasticizer of new generation has been applied as a modifier on the basis of polycarboxylates, alongside with additives-stabilizers and micro reinforcing fibres of polypropylene. Plasticizers are synthetic, water-soluble surface-active chain or reticulated polymers and copolymers, that differ from traditional ones by the type and considerably less ionic groups (quite weak polyelectrolyte), as well as by the constrained spatial structure of present lateral chains that prevent the particles of cement drawing together. In this case, except electrostatic, steric effect of pushing away of lateral chains of adsorbable macromols is realized. In the process of co-operating of cement particles with water lateral chains are slower shrouded by the products of hydration that predetermines their longterm plasticizing action. Except it, separate lateral chains in colloid solution can be slabbed from cement particles, settle on the hydratated products and continue plasticizing effect. Ethers of cellulose - derivatives of cellulose, that can be described by a general formula $/ \mathrm{C}_{6} \mathrm{H}_{7} \mathrm{O}_{2}(\mathrm{OH})_{3-\mathrm{x}}(\mathrm{OR})_{\mathrm{n}}$ /, where: $\mathrm{n}$ is a degree of polymerization, $\mathrm{x}$ is a number of the $\mathrm{OH}$ groups, kneaded in one link of macromol of cellulose (degree of substitution or etherification); $\mathrm{R}-\mathrm{CH}_{3}$ is methyl, $\mathrm{C}_{2} \mathrm{H}_{5}$ is ethyl, $\mathrm{C}_{3} \mathrm{H}_{7}-$ propyl, are used as stabilizing additives. Stereoregular structure of macromolecule and firmness of confirmatory form of its elementary link distinguishes cellulose from all row of polysaccharides, including the most firmness to chemical influences. In the mixture CREA-LF methylhydroxyetylcellulose is applied, the basic property of which is a high level of waterretaining ability. The molecules of dissolved cellulose form aqua - complexes. Ethers of cellulose as non-ionogenic surface-active material own high stabilizing ability, providing sedimentation stability of suspensions. Application of ethers of cellulose promotes the increase of adhesive behaviors of the plugging systems and decline of permeability of cement stone, as there is colmatation and ceiling of capillary pores of stone structure by cellulose gel. With the aim of increasing of deformation properties of stone composition plugging mixtures contain microreinforced fibres. Ability to microplastic deformations of composition matrix is increased by microreinforcement stipulates the higher values of energy consumptions on destruction of the stone.

It should be noted that development and application of modern plugging composite materials to which belong CREA and CREA-LF can not find out the solution for the existent problem of ensuring the required level of reliability (first of all durability) of isolating baffle. In accordance with principles of physical and chemical mechanics 
(academician P.A. Rebinder and his school), production of binding materials with the predetermined properties requires ensuring of the directed structure formation of the suspension. In industrial practice of longhole building two basic methods of improvement of the quality of plugging mortars and the stone have been widely applied. The first is based on the various methods of clinker activation (disintegrating treatment of cements; ultrasonic, hydroacoustic, hydrodynamics, electric, or magnetic activating of mixture). The second is based on the principles of water content regulation, as for example by application of packer-filters which ensure force filtration of surplus amount of mixing water from plugging suspension after completing of cementation operation [2].

As the technical state of casing (fig.2) does not allow to use traditional parker devices the authors has investigated possibility of operating the processes of structure formation of plugging-mortars by zeolite tuff application. This is implemented through dehydration of zeolite tuff which is characterized by tough crystalline alumosilicates skeleton with the cavities united to one another by open channels - windows, that are very important for the processes related to adsorption and mass transfer.

It has been found that addition of finely grounded zeolitic tuffs to the kneaded plugging suspension promotes structure formation. The process of hardening is determined by a chemosorption, which occurs on the surface of zeolite grains, and is followed by formation of crystallohydrates that strengthen a hardening structure. Depending on the concentration of the additive, the structure and operational properties of cement stone are improved due to binding of surplus water and increase of dispersible phase concentration; the setting terms at that can be shortened by $40-70 \%$.

The achievement of necessary level of reliability of isolating baffle can ensure the effective protecting of cement stone from corrosive destruction under the action of aggressive bed waters. The researches have been confirmed high sorbtion ability of fibres of thermographenite in relation to hydrocarbons including oils of Carpathian deposits. It was ascertained that depending on a type and properties of fluid and thermo baric conditions, one mass part of thermographenite can absorb on itself from 65 to 73 mass parts of unrefined oil. Thus the highviscous impenetrable for water thixotropic composition appears. Examinations of cement stone corrosion resistance were carried out in basic bed waters of oil and gas deposits of Carpathians showed that the cement stone covered by the layer of such composition did not give evidence of destruction.

The results of the researches has allowed the authors to develop the new method of liquidating cementation for old oil and gas bore holes, essence of which consists in the following. After decompression of the mouth of the borehole, a level of the formation fluid inside the production string (that can make from a few ten to a few hundred meters) is determined by one of well-known methods. The specimens are taken away from the surface of liquid and study. Mostly it is petroleum emulsion that threatens the environment. Inside the columns $50-70 \mathrm{~kg}$ of thermographenite is filling up, which absorbs oil and forms a highly viscous layer of 30-50 m thick on a fluid surface. On the formed layer, $70-100 \mathrm{~kg}$ of finely dispersed zeolite tuff is poured, which further is grown by the plugging suspension of composition mixture of CREA or CREA-LF. After the cement mixture get on a dry zeolite, filtration of the surplus kneading water happens and formation of stone structure with high operating properties speeds-up. Thus baffles of petrolized thermographenite and zeolite protect the cement stone from destruction. So, it is possible to create in boreholes the combined isolating baffles with high reliability (fig. 4). 


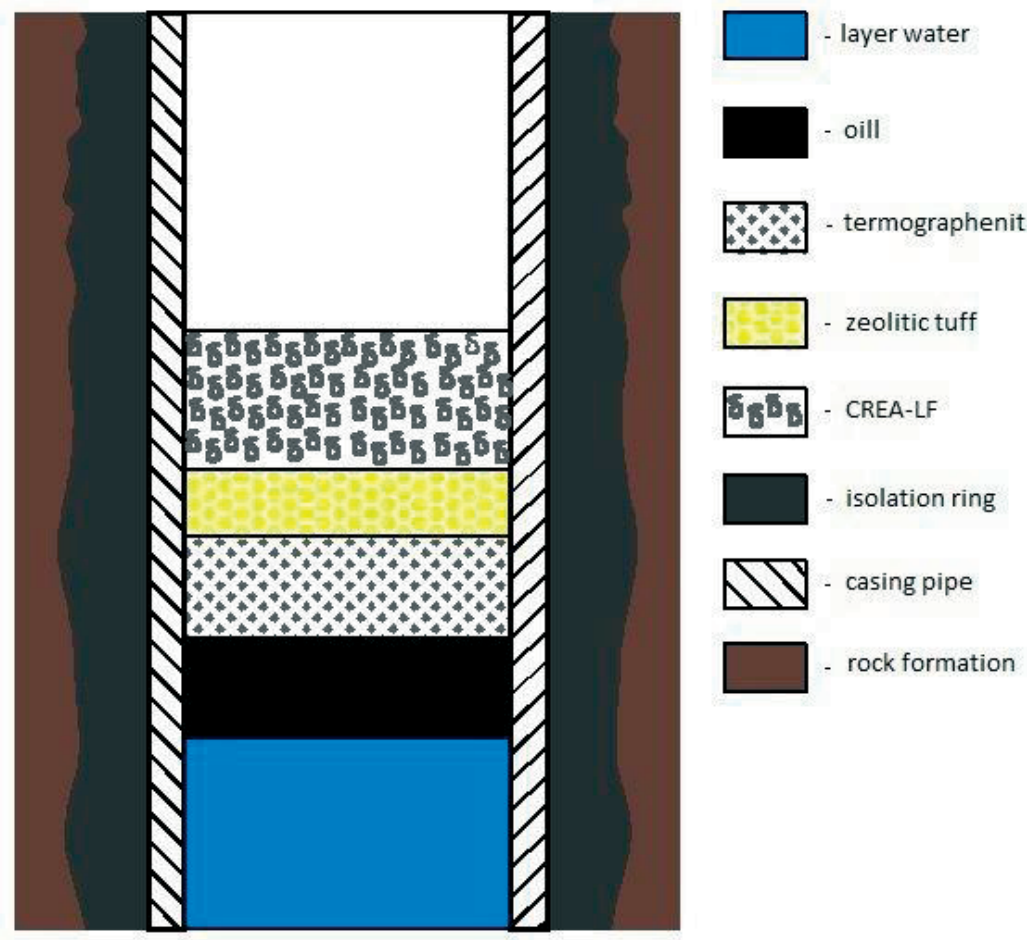

Fig. 4. Scheme of isolation screen construction in liquidation borehole

The developed materials and technology are successfully approved during implementation of isolating works in the boreholes of oil and gas deposits of Carpathians.

\section{Conclusion}

The oil and gas deposits of Carpathians are characterized by its unique mining-andgeological properties and plenty of old mining holes which require high-efficiency liquidating cementation. Summarising of results of researches in the direction of solving this problem, evidences the experience of application of the modern plugging composition materials produced by technology of dry building mixture preparation and high-efficiency sorbents such as zeolite tuff and thermographenite.

\section{References}

$1 \quad$ Nafta $i$ gaz Podkarpacia. Zarys Historii. Instytut Nafty i Gazu (Krakow), Naukowa Dumka (Kijow), 2004, pp. 570.

2 Bulatov A.I., Proselkov Yu. M., Shamanov S.A., Technika i technologiya bureniya neftianyh $i$ gazovyh skvagin. M.: OOO "Nedra-Biznescentr". 2003, pp. 1007.

3 Tershak B.A., Sobol Kh.S., Kovalchuk M.B. Struktura tamponagnyh cementiv modyfikovanyh crentamy. NAN Ukrainy. - Fizyko-mechanichnyi instytut im. G.V. Karpenka. - Mechanika I fizyka ruinuvannia budivel'nyh materialiv ta konstrukciy. Zbirnyk naukovyh prac'. Vypusk №10., Lviv, „Kameniar”, 2014. pp.551-561. 
4 Sanytskyy M.A., Sobol Kh.S., Markiv T.Ye. Modyfikovani kompozyziyni cement. NU "Lvivs'ka polytechnica". 2010, pp.130.

5 Terlyha V., Sobol Kh., Tershak B. Modified oil-well cements for casing boreholes with abnormally low stratum pressure. 18-th international conference on building materials "18.Ibausil". 12-15 September 2012. Weimar. 